\title{
BASES FOR BUILDING A SUSTAINABILITY INDICATOR SYSTEM FOR TRANSPORT
}

\author{
Alfredo Tolón-Becerra1; Isabel Otero-Pastor2; Pedro Pérez2; Alejandra \\ Ezquerra-Canalejo2; Xavier Lastra-Bravo1 \\ 1 Department of Engineering Projects. University of Almería. \\ 2 TRANSyT (Transport Investigation Centre). Polytechnic University of \\ Madrid.
}

The globalisation of sustainable development requires the use of transferable indicator systems which help in finding a balanced solution to the conflicts between the objectives of economic, environmental and social sustainability.

This paper serves as a methodological basis for building an indicator system, in phases, which enables:

- the assessment and follow-up of the sustainability of the transport sector in its threefold dimension: economic, environmental and social;

- the synchronic and diachronic comparison of the indicators;

- setting critical and desirable threshold values: and objective values for realistic progress towards those desirable values.

To achieve these objectives, we recommend using an iterative cycle of the indicator: generation and selection, technical construction, application, development and finally, communication, transfer and use.

As an example of the methodology, we show:

- an example of two blocks of indicators of a social nature.

- the development of a subset of road accident indicators, applied in several geographic areas throughout Europe and Spain.

\section{INTRODUCTION}

In recent years, the range of transport systems, infrastructures and services available in Spain has grown in response to social demand, within a climate of economic growth. This increasing trend in transport use -both for passengers and freight- has been a contributing factor in the rise in energy use and carbon dioxide emissions $\left(\mathrm{CO}_{2}\right)$. The current transport 
system, based on transport modes with high energy intensity such as road transport, has a serious impact on the environment, including air pollution and noise, as well as contributing to global warming (Sperling, 2004).

Both transport demand and greenhouse gas emissions are constantly increasing, and at a greater rate than the GDP. On the other hand, there has been some decrease in air pollution, although to a lesser degree (PérezMartínez, 2007). Unless we can dissociate transport activity from income, the use of energy in the transport sector will continue to grow (OECD, 2003). However, we have already reached the maximum elasticity of greenhouse gases in relation to the GDP, and this implies that future increases in GDP will entail more minor changes in emissions (PérezMartínez, 2006).

Technological innovations go some way towards creating a transport system that is sustainable from the environmental point of view, and there is evidence of an improvement in energy intensities, which has drastically reversed pollution trends (Lakshmanan and Xiaoli, 1997). However, it is not enough to rely on technology to obtain a sustainable transport system, and far-reaching shifts in policy and in the current regulations are required (Rodenburg et al., 2002).

The direct usefulness of a system of indicators is that it can provide information for using in processes where major mobility policies are formulated and implemented (Acutt and Dodgson, 1997). A direct link between the environmental indicator system and policy provides a solid mechanism for integrating the criteria of environmental sustainability into the decision-making process in the area of transport. This link is not only important for following up trends, but also for designing the measures themselves (Gudmundsson, 2003).

This general increase in transport activity has gone hand in hand with a rising concern about the potential threat that our current lifestyle poses to the environment and to human health (Lenz et al., 2003). As a result, a sustainable transport system needs to address the balance between economic, social and environmental considerations in order to define transport policy objectives. In particular, this system must be costefficient, respectful of the environment (pollution, land use, energy consumption and natural elements), safe (Sinha, 2003), and provide society with sufficient quality of service throughout the whole territory (fairness, social integration, etc.). 


\section{TRANSPORT INDICATOR SYSTEMS}

The European Environment Agency's TERM (Transport and Environment Reporting Mechanism) indicator system is a tool which responds to the European transport policy and to the concept of sustainable mobility. It currently comprises 40 indicators, primarily economic and environmental; however only 4 of these indicators involve social aspects, and deal with accident rates, and access to the service sector and to modes of transport.

The transport and environmental indicator system in Spain (TRAMA) is designed to measure the degree of sustainability of the Spanish transport system, and specifically analyses the demand for transport in relation with environmental quality indicators. This makes it possible to analyse trends and to formulate transport policies over the long term. It has the declared objective of reducing external effects; it is based on key sustainability indicators; and it follows the guidelines and methodology of the TERM (Pérez and Monzón, 2005). TRAMA provides a model of transport and trends and a photograph of the environmental pressures and impacts in the sphere of transport, and identifies causal factors (basically technological and socio-economical). This system measures the effectiveness of the policies, commitments and objectives adopted with regard to transport and the environment.

Finally, the Spanish Observatory for Sustainability (OSE) compiles indicators for the transport sector which deal almost exclusively with the economic and environmental implications of sustainability. The 2007 report, with a structure which mirrors the European Union's indicator system, dedicates one section to the transport sector. It includes 17 indicators, only one of which deals with the social dimension; namely fatal road accidents by age group, which is a response to the European Commission's proposal to reduce by half the number of fatalities from traffic accidents in the period between 2000-2010.

Generally speaking, we can identify three stages in the process of generating and applying sustainability indicator systems, which have led to first, second and third generation systems (Gallopín, 2006). Firstgeneration systems originated in the 80s with the work done by the OECD, and are characterised by being very theoretical, and exclusively environmental. They include an environment-based approach (air, water, earth and biodiversity), an objective-based approach (in response to legal and administrative requirements, Agenda 21), and a sector-based approach (transport, tourism, industry, etc.). Second-generation systems were developed in the 90s on a national scale, and pursue a multidimensional 
approach (economic, environmental and social) to sustainable development. In recent years, the need to link aspects of development together with its indicators has given rise to systems where the indicators are grouped, transversally and systematically, into themes or multidimensional areas (third-generation systems).

In summary, the transport indicator systems developed up to the present (TERM, TRAMA, OSE,..) basically address economic aspects (demand, growth, investments...), environmental aspects (emissions, clean technologies,...) and the interaction between the economy and the environment (eco-efficiency...). However, a balanced solution needs to be found to the conflicting objectives of economic, environmental and social sustainability, and so far, the social aspects have been very superficially addressed.

Moreover, the proliferation of sustainability indicator systems has led to a certain disparity and confusion among the different methods which makes them difficult to integrate. Greater homogeneity and uniformity is required when building indicator systems, in order to improve comparability, adjust to the structure of the current observatories, and make it easier to integrate the various sectorial systems (transport, urban planning, energy, social well-being...).

\section{METHODOLOGICAL BASES FOR BUILDING A SYSTEM OF TRANSPORT INDICATORS}

We establish the methodological bases for building an indicator system in phases with which to monitor the sustainability of the transport sector in its three aspects: economic, environmental and social. We recommend using the following iterative cycle:

1.Context of the indicator system. This must include at least a definition of the geographic scope of application; political-administrative context; and the key time periods, given that sustainable development involves constant change (Bossel, 1999).

2.Generating and selecting the indicators. This will be done on a structure classified into areas, subsystems, blocks or levels, in order to facilitate their analysis by specialisation (Bossel, 1999). The indicators will be selected based on their previous characterisation according to their suitability (significant, mature, not redundant, with adequate geographical coverage and integrable), the quality of the data required (available at a reasonable cost, reliable, and methodologically consistent), and their social 
impact (interest, resonance, whether they are understandable and easy to communicate).

3.Technical construction and application of the selected indicators. This will allow them to be quantified and compared on different scales for specific years (synchronic comparison) and to analyse trends over time (diachronic comparison). In doing this, it is important for the selection of relative indicators to include not only trends (percentage of variation over time) and the relativisation of the indicator by population and by area, but also other data and variables which help to provide a better understanding of the indicator, and to qualify its complexity.

4.Establishing critical and desirable threshold values, and objectives for realistic progress towards the desirable objectives. This will be done using reference values which allow a preliminary estimation or approximation in terms of distance.

The threshold values are considered limit; this means that in principle, there could be a negative limit or critical value, and another optimal or desirable value. The critical value indicates the minimum or maximum value that an indicator may have, below or above which there is clearly a situation of unsustainability, which is therefore the direct opposite of the desirable values corresponding to the optimal -albeit utopian- situation to be attained. As there is no official operative measurement of sustainable development, in most studies this is estimated based on the best existing situation in the scope of the study, or greater (Mega and Pedersen, 1998).

The objective values must establish some pragmatic progress towards the desirable values; this progress will be more accelerated the further they are from the desirable values in order to reach a rapid convergence. Greater efforts will be required towards the end, as we come closer to reaching the desirable values. These values or intervals are the ones we wish to attain as the ultimate objective of the policy to be applied, and they are estimated in terms of distance and convergence.

5.Communicating and using the indicator system. This involves transferring the indicators to the users (politicians, public managers, society...) to enable the results to be used in the decision-making process, thereby legitimising the indicators. In order to ensure their usefulness, they must be expressed and then submitted to debate at different levels of complexity (the most complex for experts, through to the simplest). There should be a limited number of indicators per debate (about five), with one predominant and other secondary indicators.

6.Generating new indicators. These will become progressively more complex, dense and transversal between the sectors (for example, accessibility and social well-being) and between different scales. 


\section{RESULTS}

To illustrate the methodology, we show part of the results from the beginning of the stage for generating and selecting a non-exhaustive list of indicators grouped into two blocks: accessibility to social services (Table 1 ), and road accident rate (Table 2).

Table 1. "Accessibility to social services” block

\begin{tabular}{|c|c|c|}
\hline PRESSURE (Causes) & STATE (social) & RESPONSE \\
\hline $\begin{array}{l}\text { Distance to social centres. } \\
\text { Quality of transport } \\
\text { infrastructures: distance to } \\
\text { depots for each service (train, } \\
\text { bus, service area, taxi)... } \\
\text { Quality of public and private } \\
\text { transport services: no. of } \\
\text { lines, no. of services per day, } \\
\text { waiting time between } \\
\text { services, schedules,... }\end{array}$ & $\begin{array}{l}\text { Average travel time to } \\
\text { social centres, hospitals, } \\
\text { health centres, schools, } \\
\text { universities and colleges, } \\
\text { administrative centres... }\end{array}$ & $\begin{array}{l}\text { Investment in transport } \\
\text { infrastructures, investment } \\
\text { in public transport } \\
\text { systems, building new } \\
\text { social centres closer by... }\end{array}$ \\
\hline
\end{tabular}

Table 2. "Road accident rate” block

\begin{tabular}{|c|c|c|}
\hline PRESSURE (Causes) & STATE (social) & RESPONSE \\
\hline $\begin{array}{l}\text { Quality of the road network: } \\
\text { curves, state of repair, } \\
\text { signposting... Causes } \\
\text { attributable to drivers: traffic } \\
\text { offences; driving while under } \\
\text { the influence of alcohol, } \\
\text { drugs or medicines; driving } \\
\text { licence obtained by fraud; } \\
\text { age-related problems; and } \\
\text { physical condition of driver... } \\
\text { Causes deriving from } \\
\text { vehicles: age of the vehicles, } \\
\text { design defects... }\end{array}$ & $\begin{array}{l}\text { No. of accidents involving } \\
\text { victims, without victims, } \\
\text { with fatalities... } \\
\text { Total no. of fatalities } \\
\text { broken down by sex, age } \\
\text { groups... } \\
\text { No. of black spots: per area, } \\
\text { length of road network... } \\
\text { Time taken by emergency } \\
\text { services to reach victims... }\end{array}$ & $\begin{array}{l}\text { Improvement in vigilance } \\
\text { and control: no. of police } \\
\text { officers, frequency of } \\
\text { official technical } \\
\text { inspection of vehicles, } \\
\text { licences incurring penalty } \\
\text { points, fines... } \\
\text { Improvements and new } \\
\text { designs in vehicle safety... } \\
\text { Correct use of legal drugs } \\
\text { and medicines, } \\
\text { rehabilitation programmes } \\
\text { for those involved in } \\
\text { accidents... } \\
\text { Publicity: campaigns to } \\
\text { encourage good driving } \\
\text { practices... } \\
\text { Improvement } \\
\text { emergency services... }\end{array}$ \\
\hline
\end{tabular}

Source: "European Road Safety Action Programme” (2003). "Mid-term review of the European Commission’s 2001 Transport White Paper” (2006). 
These two blocks correspond to the initial structure of the sub-system of social indicators for the transport sector ordered into a framework of pressure-state-response. The "accessibility to social services" block shows the beginnings of integration of two blocks belonging to two indicator subsystems of a different nature: transport, and social well-being. Some of the proposed response indicators recommend improving transport infrastructures (road network, public or private transport...) whereas others opt to build more service centres and to reduce average distances. This highlights the need to integrate the indicator systems.

As an example of the application of indicators, priority has been given to the "road accident rate" block, because of all the means of transport, this is the one which causes most deaths. We first approach the indicators of state before addressing the indicators of pressure and response. We have selected as the main indicator the number of fatalities in traffic accidents, as one of the EU's priorities is to decrease this figure to half between 2000 and 2010. The values have been updated to 2000, and figures for 2010 have been estimated by quadratic minimum regression (Figure 1).

It can be seen that the objective is being met, although generally more satisfactorily in the EU-15 (72 in 2006 and 51.7 in 2010) than for the EU25 (75 and 58), and that Spain is following a similar trend (71 and 54). However, this progress is not homogeneous, either in European countries (68 and 46 in Germany, compared to Lithuania, where fatalities increased to 118 and 132), or in Spanish cities (Barcelona with 60 and 36 or Madrid with 69 and 44 show greater progress than Almería with 100 and 94, or Cadiz with 96 and 99).

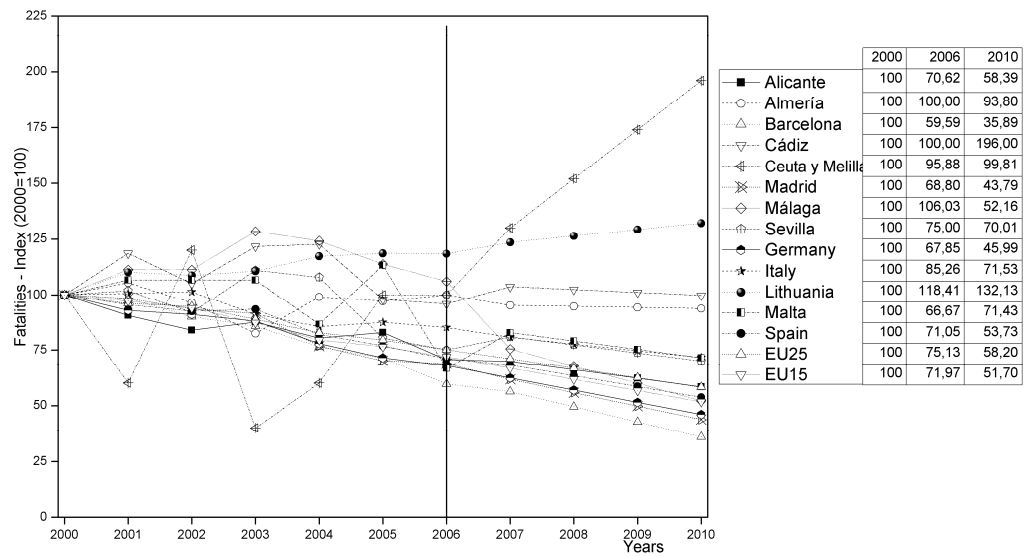

Fig. 1. Number of fatalities in road accidents updated to 2000 (\%). Evolution 2000-2010 (CARE 2008, DGT 2007). 
In addition to measuring the rate of progress, it is also necessary to measure the current situation, and to compare areas on different scales. For this reason we consider that this primary indicator should be complemented with other secondary indicators, expressed in relative terms. The first of these relativisations is by population (Figure 2).

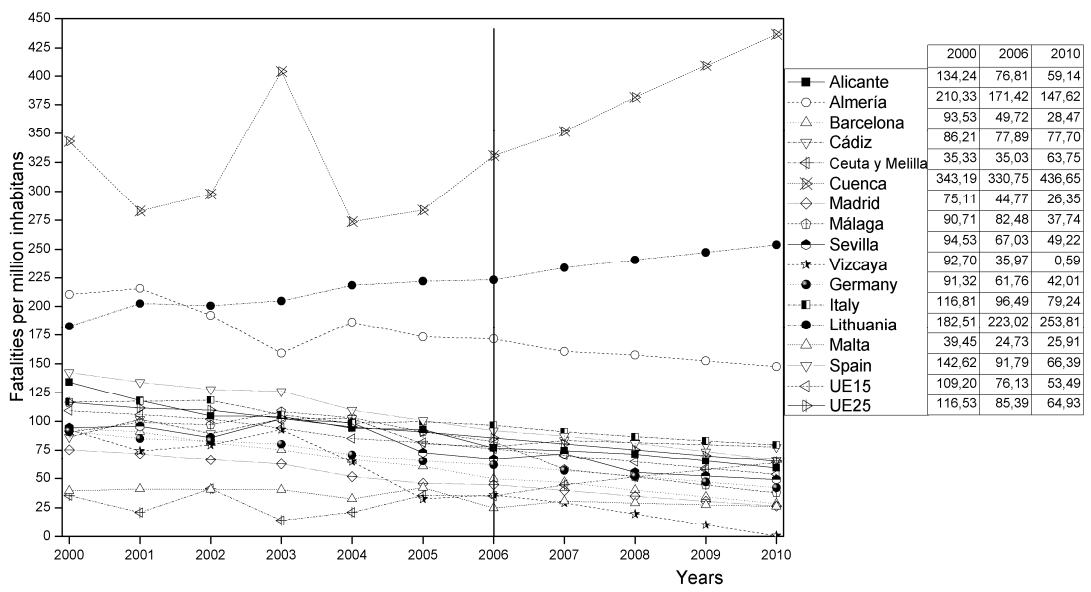

Fig. 2. Number of fatalities in road accidents per million inhabitants. Evolution 2000-2010 (CARE 2008, DGT 2007, EUROSTAT 2008, INE 2008).

In this case it can be seen that although there has been a similar rate of progress, this progress has been more irregular, and particularly there is considerable difference between the different areas. If we take 2006 as the year for synchronic comparison, we can see that the value of the EU-15 (76) is also lower than the value of the EU-25 (85) but here it is more disperse, with both extremely low values (Malta with 25) and extremely high values (Lithuania with 223). In Spain, the value is slightly higher (92) than for the EU, and widely dispersed by province (from values of around 36 in Vizcaya, through to shockingly high figures such as 330 in Cuenca, and with an ongoing upward trend).

Other relative indicators worth mentioning are the percentage of victims broken down into urban and country roads, in comparison with the total number of traffic victims; this underscores the fact that the value is always higher for country roads than for urban roads, although the values are heterogeneous (57\% in Barcelona or $72 \%$ in Madrid, compared to $97 \%$ in Avila or $94 \%$ in Cuenca, for 2006). Also worth noting is the relative indicator regarding number of fatalities for every 1000 accidents with victims (fatal and non-fatal), which is decreasing in Spain (41 in 2006, compared to 57 in 2000) and even more disperse (14 in Barcelona, 17 in 
Madrid or 25 in Vizcaya, compared to 99 in Almería or 83 in Ciudad Real).

\section{CONCLUSIONS AND DISCUSSION}

Generally speaking, the accident rate is decreasing, albeit unevenly, and with very heterogeneous values. A certain more or less pronounced negative correlation can be seen, depending on the relative indicator analysed, between the accident rate and the characteristics of the geographical area considered, according to whether it is denselypopulated, developed, urban, flat, coastal... But the great dispersion of the results highlights the need for micro-investigations which would make it possible to detect local situations (black spots...), and to break down the indicators by sex, age, proximity to major urban areas etc., and to determine their causes. This would enable non-linear and de-concentrated decisions to be taken by provincial delegations of the Interior Ministry, regional governments and local councils, among others.

In any case, the desirable value for all road accident indicators should be zero, while the critical and objective values may vary according to the geographical area considered. The critical values must be obtained in terms of distance, and the objective values in terms of distance and convergence, also expressed in absolute terms or percentage of improvement. Given that for the EU, the objective value has been fixed at a reduction coefficient of 0.5 (fatalities in 2010/fatalities in 2000), greater progress should be seen in more local areas, as the distance is greater with regards the value of the highest scope (in this case the EU). Therefore the objective reduction coefficient should be modulated using a normalised multi-criteria function depending on the population of the area considered and the distance of the relative accident rate compared to the average value for the EU. This coefficient may vary between 1 (hypothetical case of an initial accident rate of practically zero), and 0 (theoretical case of total initial accident rate for the population).

\section{REFERENCES}

1. Acutt MZ, Dodgson, JS (1997) Controlling the environment impacts of transport: matching instruments to objectives. Transpn.Res.D (2): 17-33.

2. Bossel H (1999) Indicators for Sustainable Development. Theory, Method, Applications. International Institute for Sustainable Development. Canada. 
3. European Commission (2001) White Paper - European transport policy for 2010: time to decide. Office for Official Publications of the European Communities. Luxembourg. 119pp.

4. Gallopín G (2006) Los Indicadores de Desarrollo Sostenible: Aspectos Conceptuales y Metodológicos. Ponencia realizada para el Seminario de Expertos sobre Indicadores de Sostenibilidad en la Formulación y Seguimiento de Políticas. Chile.

5. Gudmundsson H (2003) Making concepts matter: sustainable mobility and indicator systems in transport policy. International Social Science Journal 55(2): 199-217.

6. Lakshmanan TR, Xiaoli H (1997) Factors underlying transportation CO2 emissions in the U.S.A.: a decomposition analysis. Tranpn Res.D 2(1), 115.

7. Lardelli P, Luna J, Jiménez J, Bueno A, García M, Gálvez R, (2001) Age and sex differences in the risk of causing vehicle collisions in Spain, 1990 to 1999. Accident analysis and prevention 35: 261-272.

8. Lenz HP, Prüller S, Gruñen D, (2003) Means of Transportation and Their Effect on the Environment. En: D. Gruden (ed.) Traffic and Environment, Springer Verlag, Berlin, pp 107-173.

9. Mega, V. Pedersen, J (1998) Urban Sustainability Indicators. Office for Official Publications of the European Communities. Luxembourg, 49 pp.

10. OECD Environment Directorate (2003) Analysis of the links between transport and economic growth. Project on decoupling transport impacts and economic growth. Caid N. ENV/EPOC/WPNEP/T (2003) 4/FINAL, Paris, France, 94 pp.

11. Observatorio de la Sostenibilidad en España (2007) Sostenibilidad en España 2007. Ministerio de Medio Ambiente, Fundación Biodiversidad, Fundación Universidad de Alcalá. 2005. Mundi-Prensa Libros, S.A.

12. Pérez-Martínez PJ (2007) Mobility and environment in Spain. En: G. Morrison y S. Rauch (eds.) Highway and Urban Environment: Proceedings of 8th International Symposium on the Highway and Urban Environment, Springer Science, Dordrecht.

13. Pérez-Martínez PJ (2006) Mobility and environment in Spain. Are we tending towards sustainability?. R. Joumard (ed) Conference Proceeding of Environment and Transport, INRETS, Reims (France), 1 (2), 60-65.

14. Pérez PJ, Monzón A (2005) Informe sobre transporte y medio ambiente. Trama 2005. Centro de Publicaciones Secretaría General Técnica Ministerio de Medio Ambiente, Madrid, España, 108 pp.

15. Rodenburg CA, Ubbels B, Nijkamp P (2002) Policy scenarios for achieving sustainable transportation in Europe. Transport Reviews 22 (4): 449-472.

16. Sinha KS (2003) Sustainability and Urban Public Transportation. Journal of Transportation Engineering 129 (4): 331-341.

17. Sperling D (2004) Environmental impacts due to urban transport. Urban Transport and the Environment. An International Prospective, Elsevier, Oxford, pp 99-189. 